\title{
Evaluation of Different Cryoprotectants (CPAs) in Boar Semen Cryopreservation
}

\author{
Suhee $\mathrm{KIM}^{1)}$, Young-Jun LEE ${ }^{1)}$, Dong-Beom JI ${ }^{1)}$ and Yong-Jun $\mathrm{KIM}^{1) *}$ \\ I) Department of Veterinary Obstetrics and Theriogenology, College of Veterinary Medicine, Chonbuk National University, Jeonju, \\ Jeonbuk 561-756, Republic of Korea
}

(Received 12 August 2010/Accepted 14 March 2011/Published online in J-STAGE 28 March 2011)

\begin{abstract}
This study was performed to evaluate the use of dimethylacetamide (DMA) and dimethyl sulfoxide (DMSO) in boar sperm cryopreservation. Semen from eight boars was cryopreserved following treatment with 3, 5, and 7\% DMA and DMSO, and 3\% glycerol (control). After thawing, sperm conventional parameters and membrane integrities were evaluated. There were no significant differences among different DMA concentrations in all evaluations. Membrane intactness were higher in 5\% and 7\% DMSO than $3 \%$ DMSO $(P<0.05)$. Sperm motility of $5 \%$ DMSO was lower than that of $3 \%$ glycerol $(P<0.005)$, and membrane intactness were lower in $5 \%$ DMA and DMSO than $3 \%$ glycerol $(P<0.05)$. DMA and DMSO didn't improve sperm quality and glycerol remains the most useful for boar sperm cryopreservation.

KEY WORDS: boar sperm, cryopreservation, DMA, DMSO, glycerol.
\end{abstract}

Glycerol (at a concentration of 3\%) is the most commonly used cryoprotectant (CPA) for boar sperm [3], but it has toxic effects as well as contraceptive effects on sperm [8]. Its detrimental effects have stimulated the study of alternative CPAs such as N,N-dimethylacetamide (DMA) or dimethyl sulfoxide (DMSO) [2, 10]. Due to its highly hydrophilic nature and low molecular weight, DMA reduces the formation of intracellular ice crystals and increases membrane permeability, thus decreasing osmotic damage [2]. The penetration of DMSO is also rapid, due to its lower molecular weight relative to glycerol [10] and DMSO has been used to successfully cryopreserve sperm [9]. However, there are few studies on the uses of DMA and DMSO for freezing boar semen. Therefore, the objective of this study was to evaluate the effectiveness of DMA and DMSO as possible replacement for glycerol in boar semen cryopreservation.

Three CPAs were used in this study: glycerol, DMA, and DMSO (all from Sigma-Aldrich, St. Louis, MO, U.S.A.). Glycerol was used at a final concentration of 3\% as a control, and the others at final concentrations of 3, 5, and $7 \%$. We first compared the three concentrations of DMA and DMSO $(n=5)$, and the concentrations showing the best result for each CPA were then compared with $3 \%$ glycerol $(\mathrm{n}=8)$.

Ejaculate from 8 Duroc boars was collected and processed according to the straw freezing procedure [1] with some modification. Sperm-rich fractions were extended in Beltsville Thawing Solution (BTS) and were slowly cooled to $15^{\circ} \mathrm{C}$ for $3 \mathrm{hr}$. After centrifuging, the semen pellet was resuspended in lactose-egg yolk (LEY) extender. After fur-

\footnotetext{
* Correspondence to: Kim, Y.-J., Department of Veterinary Obstetrics and Theriogenology, College of Veterinary Medicine, Chonbuk National University, Jeonju, Jeonbuk 561-756, Republic of Korea.

e-mail: yjk@chonbuk.ac.kr

S. KIM and Y.-J. LEE contributed equally to this work.
}

ther cooling to $5^{\circ} \mathrm{C}$ for $90 \mathrm{~min}$, LEY-extended semen was aliquot for treatment with each CPAs and then two parts LEY-extended semen were mixed with one part freezing extenders (LEY extender containing 1.5\% Equex STM [Nova Chemical Sales, Scituate Inc., MA, U.S.A.] and the CPAs described above, $\mathrm{v} / \mathrm{v})$. The semen was loaded into $0.5-\mathrm{m} l$ straws (IMV, L'Aigle, France), and held in liquid nitrogen vapor $3 \mathrm{~cm}$ above the liquid for $20 \mathrm{~min}$. The straws were then plunged into the liquid nitrogen. After thawing the straws at $37^{\circ} \mathrm{C}$ for $20 \mathrm{sec}$ [5], thawed semen was evaluated for sperm motility [13], morphological defect, viability by eosin-nigrosin staining [4], and plasma- and acrosomalmembrane integrities. Sperm plasma-membrane integrity was assessed using 6-carboxyfluoresceindiacetate (6CFDA; Sigma-Aldrich)/propidium iodide (PI; Sigma-Aldrich) fluorescent staining [12] and analyzed by flow cytometry. CFDA+/PI- stained sperm were classified as having an intact plasma-membrane. Sperm acrosomal-membrane integrity was evaluated using a FITC-peanut agglutinin (FITC-PNA; Sigma-Aldrich)/PI fluorescent staining following a modification $[6,11]$ and analyzed using flow cytometry. Analyzed sperm were classified into the following categories: viable acrosome-intact (PNA-/PI-); viable acrosome-reacted (PNA+/PI-); dead acrosome-reacted $(\mathrm{PNA}+\mathrm{PI}+)$ and total acrosome-reacted (PNA+). Flow cytometric analyses were performed using a FACScalibur flow cytometer (Becton Dickinson, San José, CA, USA) and Cell Quest Pro software (Becton Dickinson). Statistical analysis of the data was performed using SPSS software (version 15.0 for Windows; SPSS Inc., Chicago, IL, U.S.A.). One-way repeated-measures analysis of variance and Bonferroni's test were used for data with a normal distribution. Friedman test and Wilcoxon signed ranks test were used in the case of a violation of a normal distribution. Statistical significance was set at $P<0.05$ and all data were presented as the mean \pm standard error of the mean (SEM).

In comparisons among CPA concentrations, there was no 
Table 1. Evaluation of frozen-thawed sperm following different concentrations of each CPA

\begin{tabular}{|c|c|c|c|c|c|c|c|c|c|}
\hline \multirow[t]{2}{*}{ CPAs } & \multicolumn{2}{|c|}{ Motility (\%) } & \multirow{2}{*}{$\begin{array}{c}\text { Viability } \\
(\%)\end{array}$} & \multirow{2}{*}{$\begin{array}{c}\text { Morphological } \\
\text { defect }(\%)\end{array}$} & \multirow{2}{*}{$\begin{array}{l}\text { Intact plasma } \\
\text { membrane } \\
(\%)\end{array}$} & \multicolumn{4}{|c|}{ Acrosomal membrane integrity (\%) } \\
\hline & $\begin{array}{c}\text { Total } \\
\text { motilty }\end{array}$ & $\begin{array}{c}\text { Progressive } \\
\text { motility }\end{array}$ & & & & $\begin{array}{c}\text { Viable } \\
\text { acrosome- } \\
\text { intact }\end{array}$ & $\begin{array}{l}\text { Viable } \\
\text { acrosome- } \\
\text { reacted }\end{array}$ & $\begin{array}{c}\text { Dead } \\
\text { acrosome- } \\
\text { reacted }\end{array}$ & $\begin{array}{c}\text { Total } \\
\text { acrosome- } \\
\text { reacted }\end{array}$ \\
\hline $3 \%$ DMA & $40.00 \pm 4.18$ & $35.00 \pm 4.18$ & $58.90 \pm 3.17$ & $34.30 \pm 1.69$ & $30.29 \pm 3.95$ & $30.98 \pm 3.57$ & $2.63 \pm 0.65$ & $26.23 \pm 2.97$ & $28.86 \pm 3.00$ \\
\hline $5 \%$ DMA & $44.00 \pm 2.92$ & $39.00 \pm 2.92$ & $58.96 \pm 1.81$ & $31.50 \pm 2.67$ & $35.45 \pm 3.46$ & $35.90 \pm 4.69$ & $2.57 \pm 0.77$ & $28.71 \pm 2.33$ & $31.27 \pm 2.68$ \\
\hline $7 \%$ DMA & $36.00 \pm 6.96$ & $31.00 \pm 6.96$ & $49.80 \pm 4.33$ & $36.53 \pm 2.71$ & $29.76 \pm 6.04$ & $30.31 \pm 6.98$ & $1.98 \pm 0.46$ & $38.36 \pm 3.74$ & $40.34 \pm 3.71$ \\
\hline $3 \%$ DMSO & $29.00 \pm 6.20$ & $24.00 \pm 6.20$ & $57.04 \pm 4.09$ & $31.10 \pm 2.92$ & $23.87 \pm 1.85^{\mathrm{a})}$ & $24.33 \pm 2.44^{\text {a) }}$ & $2.42 \pm 0.23$ & $23.17 \pm 2.74$ & $25.58 \pm 2.93$ \\
\hline $5 \%$ DMSO & $28.00 \pm 5.61$ & $23.00 \pm 5.61$ & $60.82 \pm 9.24$ & $36.10 \pm 1.03$ & $\left.30.19 \pm 2.98^{b}\right)$ & $30.28 \pm 3.47^{b)}$ & $2.52 \pm 0.25$ & $23.47 \pm 3.28$ & $25.99 \pm 3.48$ \\
\hline 7\% DMSO & $28.00 \pm 4.64$ & $23.00 \pm 4.64$ & $59.02 \pm 7.22$ & $39.52 \pm 3.88$ & $\left.29.86 \pm 2.89^{\mathrm{b}}\right)$ & $29.89 \pm 1.75^{\mathrm{b})}$ & $2.42 \pm 0.50$ & $25.12 \pm 2.76$ & $27.54 \pm 2.90$ \\
\hline
\end{tabular}

Different superscripts indicate significant differences among concentrations within each CPAs: a,b) $P<0.05$.

Table 2. Evaluation of frozen-thawed sperm treated by different CPAs

\begin{tabular}{|c|c|c|c|c|c|c|c|c|c|}
\hline \multirow[t]{2}{*}{ CPAs } & \multicolumn{2}{|c|}{ Motility (\%) } & \multirow{2}{*}{$\begin{array}{c}\text { Viability } \\
(\%)\end{array}$} & \multirow{2}{*}{$\begin{array}{c}\text { Morphological } \\
\text { defect }(\%)\end{array}$} & \multirow{2}{*}{$\begin{array}{c}\text { Intact plasma } \\
\text { membrane } \\
(\%)\end{array}$} & \multicolumn{4}{|c|}{ Acrosomal membrane integrity (\%) } \\
\hline & $\begin{array}{c}\text { Total } \\
\text { motilty }\end{array}$ & $\begin{array}{c}\text { Progressive } \\
\text { motility }\end{array}$ & & & & $\begin{array}{l}\text { Viable } \\
\text { acrosome- } \\
\text { intact }\end{array}$ & $\begin{array}{l}\text { Viable } \\
\text { acrosome- } \\
\text { reacted }\end{array}$ & $\begin{array}{c}\text { Dead } \\
\text { acrosome- } \\
\text { reacted }\end{array}$ & $\begin{array}{c}\text { Total } \\
\text { acrosome- } \\
\text { reacted }\end{array}$ \\
\hline $3 \%$ Glycero & $48.13 \pm 3.65^{a)}$ & $41.88 \pm 3.40^{\mathrm{a})}$ & $65.72 \pm 1.67$ & $28.13 \pm 2.42$ & $51.80 \pm 2.61^{\mathrm{c})}$ & $51.54 \pm 2.72^{\mathrm{e})}$ & $4.82 \pm 1.03^{\mathrm{e})}$ & $18.5 \pm 1.56^{\mathrm{e})}$ & $23.31 \pm 1.78^{\mathrm{c})}$ \\
\hline $5 \%$ DMA & $45.63 \pm 1.99^{a)}$ & $40.63 \pm 2.20^{\mathrm{a})}$ & $59.85 \pm 1.63$ & $32.38 \pm 3.30$ & $38.01 \pm 3.06^{\mathrm{d})}$ & $39.03 \pm 3.83^{f)}$ & $3.25 \pm 0.69^{\mathrm{e})}$ & $28.04 \pm 1.81^{\mathrm{f})}$ & $31.28 \pm 2.19^{\mathrm{d})}$ \\
\hline $5 \%$ DMSO & $26.88 \pm 3.53^{\mathrm{b})}$ & $21.25 \pm 3.50^{\mathrm{b})}$ & $59.01 \pm 2.65$ & $35.56 \pm 2.91$ & $30.89 \pm 1.98^{d)}$ & $30.49 \pm 2.24^{\mathrm{f})}$ & $3.37 \pm 0.67^{f)}$ & $24.05 \pm 2.11^{\mathrm{f} f}$ & $27.42 \pm 2.47^{\mathrm{c})}$ \\
\hline
\end{tabular}

Within a column, different superscripts indicate significant differences: a,b) $P<0.005$; c,d) $P<0.01$; e,f) $P<0.05$.

difference among samples treated with the three DMA concentrations in all evaluations $(P>0.05$; Table 1). Samples treated with $5 \%$ and $7 \%$ DMSO had a higher proportion of plasma membrane-intact and viable acrosome-intact sperm after freeze-thawing than samples treated with 3\% DMSO $(P<0.05)$, but the other parameters were not significantly different among the three DMSO concentrations. Although the differences were not significant, 5\% DMA and 5\% DMSO treatments showed better results than the other CPA concentrations and were selected for comparison with 3\% glycerol. In comparisons among different CPAs, sperm total and progressive motility for DMA treatment were not different from those for glycerol $(P>0.05)$, and those for DMSO were decreased compared with glycerol (Table 2; $P<0.005)$. The proportion of plasma membrane-intact and viable acrosome-intact sperm decreased in DMA and DMSO compared with glycerol $(P<0.05)$.

These results were different from previous reports that 5\% DMA can successfully replace glycerol for boar semen cryopreservation [3]. Contrary to finding that DMA or DMSO could be used as an alternative CPA for freeze-thawing in stallions $[14,15]$, DMA and DMSO decreased sperm quality during freeze-thawing compared with glycerol in boar sperm. There appears to be considerable interspecies variation in the relative permeability of CPAs. Interestingly, DMSO gave a good sperm viability but low sperm motility as compared to other CPA. Sperm can be nonmotile but viable. DMSO might induce sperm having these characteristic much more than other CPA. These sperm might indicate a transitional phase beginning to be dead. Such moribund sperm should be considered part of the dead sperm population because they are, in fact, dead on the basis of their functional capacity [7]. The proportion of viable acrosome-reacted sperm decreased in DMSO $(P<0.05)$, but the number of viable acrosome-reacted sperm was very low for all CPAs. Likewise, the proportion of dead acrosomereacted sperm increased in DMA and DMSO $(P<0.05)$ with an increase in the proportion of total acrosome-reacted sperm compared with glycerol. This might indicate that DMA or DMSO cause death of viable acrosome-reacted sperm or deterioration of the acrosome after death of viable acrosome-intact sperm, rather than prevention of acrosomal exocytosis. In conclusion, this study demonstrated that DMA and DMSO have no beneficial effects on boar sperm cryopreservation compared with glycerol. Further study is required to develop suitable CPAs as glycerol replacements in frozen-thawed boar semen.

\section{REFERENCES}

1. Almlid, T. and Johnson, L. A. 1988. Effects of glycerol concentration, equilibration time and temperature of glycerol addition on post-thaw viability of boar spermatozoa frozen in straws. J. Anim. Sci. 66: 2899-2905.

2. Ball, B. A. and Vo, A. 2001. Osmotic tolerance of equine spermatozoa and the effects of soluble cryoprotectants on equine sperm motility, viability, and mitochondrial membrane potential. J. Androl. 22: 1061-1069.

3. Bianchi, I., Calderam, K., Maschio, E. F., Madeira, E. M., da Rosa Ulguim, R., Corcini, C. D., Bongalhardo, D. C., Correa, E. K., Lucia, T., Jr., Deschamps, J. C. and Correa, M. N. 2008. Evaluation of amides and centrifugation temperature in boar semen cryopreservation. Theriogenology 69: 632-638. 
4. Bucak, M. N., Atessahin, A., Varisli, O., Yuce, A., Tekin, N. and Akcay, A. 2007. The influence of trehalose, taurine, cysteamine and hyaluronan on ram semen Microscopic and oxidative stress parameters after freeze-thawing process. Theriogenology 67: 1060-1067.

5. Carvajal, G., Cuello, C., Ruiz, M., Vazquez, J. M., Martinez, E. A. and Roca, J. 2004. Effects of centrifugation before freezing on boar sperm cryosurvival. J. Androl. 25: 389-396.

6. de Mercado, E., Hernandez, M., Sanz, E., Rodriguez, A., Gomez, E., Vazquez, J. M., Martinez, E. A. and Roca, J. 2009. Evaluation of l-glutamine for cryopreservation of boar spermatozoa. Anim. Reprod. Sci. 115: 149-157.

7. Garner, D. L. and Johnson, L. A. 1995. Viability assessment of mammalian sperm using SYBR-14 and propidium iodide. Biol. Reprod. 53: 276-284.

8. Holt, W. V. 2000. Basic aspects of frozen storage of semen. Anim. Reprod. Sci. 62: 3-22.

9. Kundu, C. N., Chakraborty, J., Dutta, P., Bhattacharyya, D., Ghosh, A. and Majumder, G. C. 2000. Development of a simple sperm cryopreservation model using a chemically defined medium and goat cauda epididymal spermatozoa. Cryobiology 40: $117-125$.
10. Lovelock, J. E. and Bishop, M. W. 1959. Prevention of freezing damage to living cells by dimethyl sulphoxide. Nature 183: 1394-1395.

11. Nagy, S., Jansen, J., Topper, E. K. and Gadella, B. M. 2003. A triple-stain flow cytometric method to assess plasma- and acrosome-membrane integrity of cryopreserved bovine sperm immediately after thawing in presence of egg-yolk particles. Biol. Reprod. 68: 1828-1835.

12. Ricci, G., Perticarari, S., Fragonas, E., Giolo, E., Canova, S., Pozzobon, C., Guaschino, S. and Presani, G. 2002. Apoptosis in human sperm: its correlation with semen quality and the presence of leukocytes. Hum. Reprod. 17: 2665-2672.

13. Rota, A., Strom, B. and Linde-Forsberg, C. 1995. Effects of seminal plasma and three extenders on canine semen stored at 4 degrees C. Theriogenology 44: 885-900.

14. Squires, E. L., Keith, S. L. and Graham, J. K. 2004. Evaluation of alternative cryoprotectants for preserving stallion spermatozoa. Theriogenology 62: 1056-1065.

15. Vidament, M., Daire, C., Yvon, J. M., Doligez, P., Bruneau, B., Magistrini, M. and Ecot, P. 2002. Motility and fertility of stallion semen frozen with glycerol and/or dimethyl formamide. Theriogenology 58: 249-251. 